\title{
Numerical simulation of Effect of Contact Pressure on Mechanical Behavior of Gas Diffusion Layers (GDL) and PFSA Membrane Assembly
}

\author{
Mohamed Karim Ettouhami ${ }^{1, *}$, Adil Atifi ${ }^{1}$, Hamid Mounir ${ }^{2}$ and Yassine Amadane ${ }^{2}$ \\ ${ }^{1}$ Centre de Recherche en Sciences et Technologies de l'Ingénieur et de la Santé, ENSET, Mohammed V \\ University of Rabat, Morocco \\ ${ }^{2}$ Research Team EMISys, Research Center Engineering 3S, Mohammadia School of Engineers, Mohammed V \\ University of Rabat, Morocco
}

\begin{abstract}
In this study, a Finite Element model has been implemented based on numerical modelling simulations to predict the mechanical behaviour of a representative unit of the fuel cell stack. The GDL deformation has been modelled as a combination of elastic deformation and fibres slippage. Mechanical stresses distribution and deformation are presented concerning the previous model work 1 with nonlinear orthotropic behaviour of the GDL. The results also show that the state of the stresses in the membrane are highly heterogeneous and largely exceed its elastic limit. The results show that the influence of the temperature variation is not significant in generating stresses. However, the influence of the moisture variation is very significant in generating stresses. Therefore, the increase in relative humidity from $30 \%$ to $90^{\circ} \%$ at $\mathrm{T}=25^{\circ} \mathrm{C}$ causes an increase in the maximum Von Mises stress of $0.0836 \mathrm{MPa}$.
\end{abstract}

Keywords: PEMFC Fuel Cell, GDL intrusion, Stress, PFSA membrane, clamping force.

\section{Introduction}

A Proton Exchange Membrane Fuel Cell is a mechanically constrained stack composed of several heterogeneous elements ${ }^{1}$. There are two causes of the membrane and GDL degradation: The presence of transition metals in the membrane catalyzes the conversion of $\mathrm{H}_{2} \mathrm{O}_{2}$ in radicals causing chemical degradation of the membrane. On the other hand, the risk of mechanical damage to the gas diffusion layers and the membrane is very is complicated, and it strongly relies on degradation, e. g: carbon corrosion and radical attack. The chemical properties of the GDL and membrane are sharply changed, which lead to eventual failure of their physical properties. Indeed, the variation of internal stresses and contact pressure between the assembly elements of a PEMFC fuel cell causes larges stains ${ }^{2}$. This result is produced by the changes in its mechanical, electrochemical and thermal characteristics. Also, these changes affect the rate of mass transportation and heat transfer. This influence the performances and the lifetime of fuel cells ${ }^{3-6}$.

Moreover, the inhomogeneous compression stresses of GDL create many opposing effects. An insufficient contact pressure may result in sealing problems, such as fuel leakage and high contact resistance ${ }^{7}$, which cause not only performance losses but also lead to potentially dangerous situations ${ }^{8}$. On the other hand, excessive contact pressures may squeeze the relative thin (GDL), leads to destroying their pore size and blocks the mass transportation ${ }^{9}$. In this sense, TT ching and al. ${ }^{10}$ presented a clamping method using finite element analysis (FEA), to generate a uniform distribution of the clamping pressure in a practical proton exchange membrane fuel cell (PEMFC).

Based on measurements and Monte Carlo simulation, L. Peng et al. ${ }^{11}$ found that non-uniform contact pressure distribution between the bipolar plate (BP) and (GDL) could result from dimensional errors of metallic bipolar plate and GDL. Moreover, A. El Kharouf and R. Steinberger Wilckens ${ }^{12}$ conducted a study using three samples sets of GDL were tested in situ under varied clamping pressure levels to demonstrate the change in the performances of MEAs with various types of GDLs, and relates the properties of the GDL to the behavior of the MEA under compression. Therefore, the development of diffusion media needs more attention before the widespread commercialization of PEM fuel cells ${ }^{13}$.

On the other hand, as GDL intrusion in the channel is one of the consequences of the inhomogeneous contact pressure between GDL and bipolar plate. This phenomenon reduces the hydraulic diameter of the reactive gas channels, a direct 
consequence of the GDL intrusion into the channel can be seen as an increase in the inlet gas pressure drop, making it more difficult to discharge liquid water out of the channel ${ }^{14,15}$. Indeed, S. Haase and M. Rauber ${ }^{16}$ proposed an excellent study to evaluate the effect of GDL intrusion on the pressure drop via exsitu determination of GDL intrusion using CFD simulation. Therefore, the inhomogeneous GDL intrusion, induced by cracked fibers that extend into the channel, dominates the flow at higher clamping pressures and leads to the exponential increase in pressure drop in the differential pressure method ${ }^{17}$. Also, the effect of operating temperature and relative humidity on fuel cell performance is largely studded 18-27.

Palo A. Garcia Salaberri and al. ${ }^{28}$ proposed a finite element model which fully incorporates the nonlinear orthotropic characteristics of the GDL, thereby show that the linear isotropic models tend to overestimate the porosity and the partial intrusion of the GDL in the channel region. However, the model presented here assumes a constant hydration level of the membrane throughout the compression process; in real applications, this may not be necessarily true. Indeed, the mechanical characterization of the GDL exhibits significant differences between authors ${ }^{29}$. Moreover slipping fibers during clamping phase are not adopted in the literature that may lead to incorrect predictions in terms of interfacial contact pressure distributions.

Understanding the fuel cell stack design on a large scale from a mechanical point of view contributes to predicting the degradation of the core of the cell, in particular, the membrane and GDL on

a

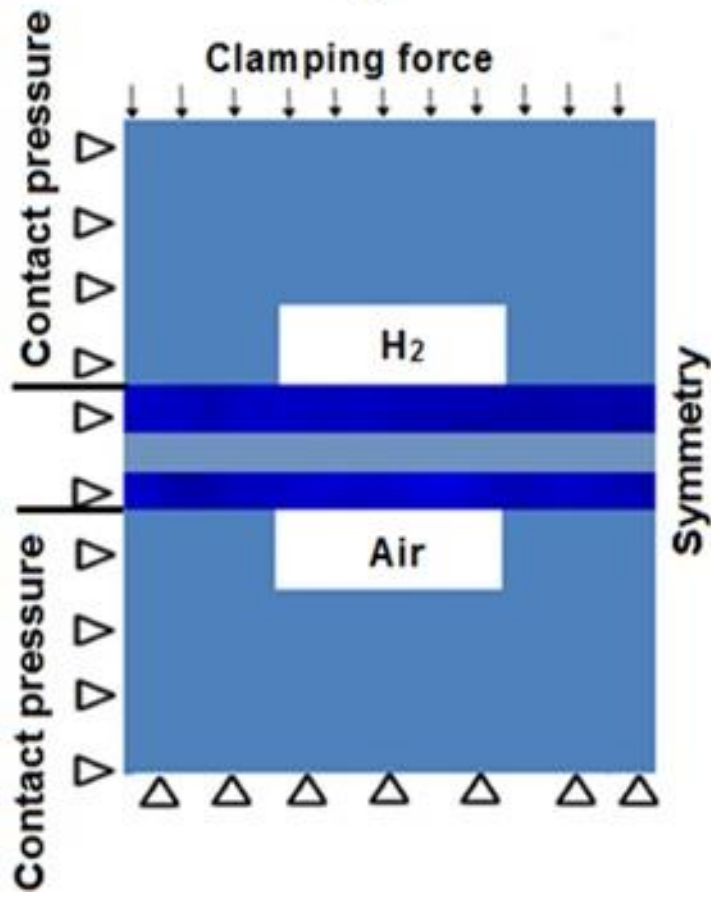

one side, and the optimization of the stack design and dimensioning of the components on another side ${ }^{30}$. We carried out a two-dimensional hydrothermomechanical approach using the finite element method, taking into account the nonlinear orthotropic behavior of the diffusion layer (GDL). The objective is to quantify and locate the stresses distribution as well as the estimation of the intrusion of the GDL into the gas channel caused by the transient operation of a fuel cell and contact pressure between GDL and bipolar plate. The effects of the temperature and relative humidity on the membrane and GDL performance are analyzed.

\section{Model description}

The mechanical behavior of a whole PEMFC stack is assimilated to the one of its unit cells ${ }^{31}$, where a fixed displacement condition was applied to the endplate (Figure. 2(a)). Figure.2(b) shows the size of the computational domain that is reduced to a typical unit cell of a PEMFC which is made of a membrane sandwiched between two electrodes gas diffusion layers' assembly (GDE) ${ }^{32}$. The proposed model is based on the FEM method for the plane stress mechanical structural module with thermal expansion using the commercial COMSOL Multiphysics software. Therefore, FEM simulations were conducted to predict the cell stress and deformation during variation of the membrane hydration level on one side, and during variation of the temperature from the ambient temperature. On the other side, the total thickness reduction of the GDL has been modeled as a combination of elastic deformation and slippage of carbon fibers 33

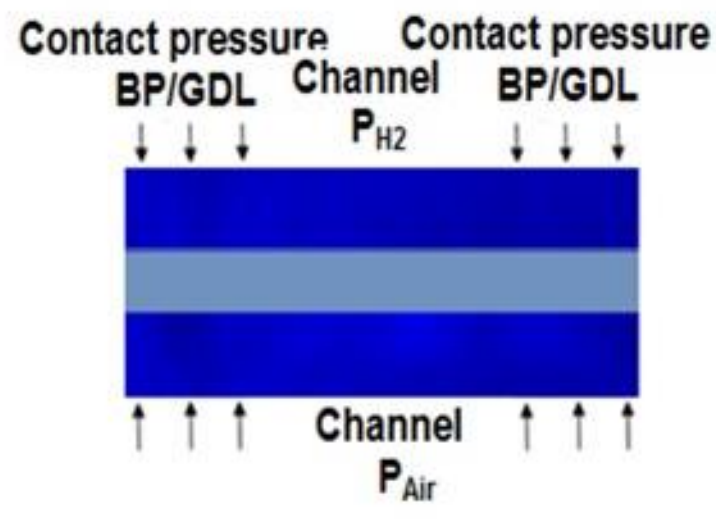

Figure 1. (a) Schematic representations of typical single cell and (b) Computational domain for FEM simulation

Table 1. Geometric parameters for the Multiphysics performances model. 


\begin{tabular}{|l|l|}
\hline Membrane thickness & $50 \mu \mathrm{m}$ \\
\hline Electrode thickness & $10 \mu \mathrm{m}$ \\
\hline GDL thickness & $190 \mu \mathrm{m}$ \\
\hline Land width & $1 \mathrm{~mm}$ \\
\hline
\end{tabular}

Hygro-thermomechanical modelling of the membrane

The membrane used in the model is the Nafion per Fluorosulphonic acid of Dupont de Nemours N112. In the context of linear elasticity, we assume that the total deformation tensor is the sum of the contribution of mechanical and hygro-thermal deformations ${ }^{32}$.

$$
\varepsilon_{i j}=\varepsilon_{i j}^{M}+\varepsilon_{i j}^{T}+\varepsilon_{i j}^{R H}
$$

The elastic displacement in an isotropic medium, according to Hooke's law, is given as follows:

$$
\varepsilon_{i j}^{M}=\frac{1+v}{E} \sigma_{i j}-\frac{v}{E} \delta_{i j} \sigma_{k k}
$$

The thermal deformations depend on the coefficient of thermal expansion $(\alpha)$ of the membrane, are given according to the following expression ${ }^{33}$ :

$\varepsilon_{i j}^{T}=\alpha\left(T-T_{0}\right) \delta_{i j}$

With

$$
\delta_{i j}=\left\{\begin{array}{l}
1 \text { si } i=j \\
0 \text { si } i \neq j
\end{array}\right.
$$

$\delta \mathrm{ij}$, is the Kronecker symbol

$\alpha$ : is the linear thermal expansion Coefficient $\left(\mathrm{K}^{-1}\right)$, $\mathrm{T}_{0}$ : is taken as a reference temperature and $\mathrm{T}$ as the actual temperature,

$\mathrm{RH}$ : is the relative humidity

The hydrothermal strain is given by the following equation:

$$
\varepsilon_{i j}^{R H}=\beta_{i j}\left(C-C_{\mathrm{o}}\right)
$$

Where $\beta_{i j}$ : is the tensor swelling produced by the moisture absorption, for isotropic material:

$\beta_{i j}=\beta \delta_{i j}$

$\mathrm{C}$ : represents the relative humidity and $\mathrm{C}_{0}$ is the reference value.

However, the calculation of the swelling strains is challenging to implement in FEM modeling since COMSOL Multiphysics, which is similar to most of the commercial software package, can only simulate the expansion caused by the temperature field change. Also, in the fuel cell stack, the influence of the temperature variation in GDL intrusion was found negligible according to the Multiphysics approach ${ }^{6}$. In this sense, we propose to separate both thermal and swelling strains. Therefore, we consider the thermal coefficient expansion as a swelling expansion coefficient. Then, the change of membrane temperature is converted to the change of membrane moisture.

Table 2. Membrane properties used in finite element analysis, Y. Tang. $2006^{12}$.

\begin{tabular}{|l|l|l|l|l|l|}
\hline $\begin{array}{l}\text { Thickness } \\
(\mathrm{m})\end{array}$ & $\begin{array}{l}\text { Young modulus } \\
(\mathrm{Mpa})\end{array}$ & $\alpha(1 / \mathrm{k})$ & $(1 / \%)$ & $\begin{array}{l}\text { Density } \\
\left(\mathrm{Kg} / \mathrm{m}^{3}\right)\end{array}$ & $\begin{array}{l}\text { Poisson's } \\
\text { coefficient }\end{array}$ \\
\hline $\mathbf{5 0 e ^ { - 6 }}$ & $\begin{array}{l}\text { E }(\mathrm{RH}, \mathrm{T}) \\
\text { Table.5 }\end{array}$ & $121 \mathrm{e}^{-6}$ & $2300 \mathrm{e}^{-6}$ & 2000 & 0.25 \\
\hline
\end{tabular}

Table 3. Young modulus of the Nafion membrane 112 according to the work of A. Kusoglu.2007 ${ }^{26}$.

\begin{tabular}{|l|l|l|}
\hline Young Modulus (MPa) & \multicolumn{2}{c|}{$\begin{array}{c}\text { Humidity relative } \\
\text { (RH) }\end{array}$} \\
\hline Temperature & $30 \%$ & $90 \%$ \\
\hline $\mathbf{T}=\mathbf{2 5}{ }^{\circ} \mathbf{C}$ & 197 & 121 \\
\hline
\end{tabular}

On the other hand, the PFSA membrane is an elastoplastic material that has yield criterion and hardening model settings. The yield criterion is interpreted as an equivalent stress $\sigma \mathrm{e}$. As a yield function, the Von Mises function was written as follows:

$$
\sigma_{I M}=\sqrt{\frac{\left(\sigma_{1}-\sigma_{2}\right)^{2}+\left(\sigma_{2}-\sigma_{3}\right)^{2}+\left(\sigma_{3}-\sigma_{1}\right)^{2}}{2}}
$$

$\sigma 1, \sigma 2$ et $\sigma 3$, these are the main constraints

$$
\sigma_{M}(R H, T)=E(R H, T) \cdot \varepsilon_{M}(R H, T)
$$

A generalized planar constraint condition is imposed in our simulations:

$$
\sigma_{x z}=\sigma_{z x}=\sigma_{y z}=\sigma_{z y}=\sigma_{z z}=0
$$

Thermo-mechanical modelling of the gas diffusion layers (GDL) 
According to mechanical study ${ }^{29}$, GDL was considered of linear orthotropic behavior. Unlike the isotropic case where Young's modulus, the shear modulus and the Poisson's coefficient are coupled, these parameters are independent in the orthotropic case and must be determined separately.

However, due to its microstructure based on carbon fibers having orthotropic properties, the microstructure of the TGP-H-60 carbon paper is deformed nonlinearly as a function of the compression load. This nonlinear deformation is a complex combination of elastic deformations on one side and slipping fibers on the other side.
The relative elongation of the Toray-60 type carbon paper under the load was estimated according to the experimental study ${ }^{33}$.

$\varepsilon_{y}=\frac{\Delta L}{L_{0}}=0.449\left(1-\exp \left(-1.063^{*} \mathrm{P}_{\text {conact }}\right)\right)$

$\mathrm{P}_{\text {contact }}$ is the contact pressure between bipolar plate and GDL

The high porosity of the GDL (78\%) makes it possible to neglect the constraints arising from the variation of the moisture tau. Therefore stress tensile is given as follow ${ }^{19}$ :

$$
\left\{\begin{array}{l}
d \sigma_{x} \\
d \sigma_{y} \\
d \tau_{x y}
\end{array}\right\}=\left[\begin{array}{ccc}
E_{x} & 0 & 0 \\
0 & E_{y}\left(\varepsilon_{y}\right) & 0 \\
0 & 0 & G_{x y}
\end{array}\right]\left[\begin{array}{l}
d \varepsilon_{x} \\
d \varepsilon_{y} \\
d \gamma_{x y}
\end{array}\right]-\frac{E \alpha^{\prime} \Delta T}{1-v}\left[\begin{array}{l}
1 \\
1 \\
0
\end{array}\right]
$$

Table 4. GDL-TORAY-60 properties used in finite element analysis for GDL-TORAY-60

\begin{tabular}{|c|c|c|c|}
\hline $\begin{array}{c}\text { Thickness } \\
(\mathrm{m})\end{array}$ & $\begin{array}{c}\text { Linear thermal expansion Coefficient } \\
(1 / \mathrm{k})\end{array}$ & $\begin{array}{c}\text { Poisson's } \\
\text { coefficient }\end{array}$ & $\begin{array}{c}\text { Density } \\
\left(\mathrm{Kg} / \mathrm{m}^{3}\right)\end{array}$ \\
\hline $190 \mathrm{e}^{-6}$ & $-0.8 \mathrm{e}^{-6}$ & 0 & 450 \\
\hline
\end{tabular}

\section{Hypothesis and boundary conditions}

With the hypothesis of associating the thermophysical characteristics of the electrode with the GDL, viewed the small thickness of the electrode. Consequently, the thickness proposed in our modelling corresponds to a GDL Toray-60, associated with an electrode with a thickness of $10 \mu \mathrm{m}$, which leads to a GDE assembly of $200 \mu \mathrm{m}$. In this case, the contact between the different elements of the model is assumed with friction. The mechanical characteristics are those adopted by J. Kleemann ${ }^{29}$ used for linear orthotropic behaviour of GDE. However, in the case of nonlinear orthotropic of GDL, $E_{y}\left(\varepsilon_{y}\right)$ was determined based on the empirical correlation (9), as well an imposed displacement can be deduced.

Table 5. Young modulus of the GDL $\left(E_{y}\right)$ as a function of contact pressure.

\begin{tabular}{|c|c|c|}
\hline Contact pressure $(\mathrm{MPa})$ & $\begin{array}{c}\text { Imposed displacement } \\
(\mathrm{mm})\end{array}$ & $\begin{array}{c}\boldsymbol{E}_{\boldsymbol{y}}\left(\boldsymbol{\varepsilon}_{\boldsymbol{y}}\right) \\
(\mathrm{MPa})\end{array}$ \\
\hline 1 & 0.058 & 3.4 \\
\hline 3 & 0.086 & 6.96 \\
\hline 6 & 0.086 & 6.96 \\
\hline 10 & 0.089 & 22.27 \\
\hline
\end{tabular}

Symmetry boundary conditions for gas pressure are used at left, and right edges of de membrane (1bar) and pure Hydrogen is used as fuel In our simulations we take account the gas pressures on the channels: $\mathrm{P}_{\text {Air }}=\mathrm{P}_{\mathrm{H} 2}=0.3$ bar.

\section{Results and discussion}

Effect of the contact pressure on GDL intrusion into the channel

Figure 2 shows the vertical displacement of the upper part of the GDL following an imposed displacement of $0.089 \mathrm{~mm}$ for case $\mathrm{P}=3 \mathrm{MPa}$. It is observed that the intrusion of the GDL into the channel is approximately $\mathrm{I}_{\mathrm{GDL}}=28 \mu \mathrm{m}$ at an operating temperature of $\mathrm{T}=25^{\circ} \mathrm{C}$ and $\mathrm{RH}=30 \%$, while the intrusion of the membrane is neglected as shown in Figure 3. Indeed, GDL is more deformed than the membrane due to the difference in Young's modulus $\left(\mathrm{E}_{\mathrm{y}(\mathrm{GDE})}<\mathrm{E}_{\text {membrane }}\right.$ ) due to the high membrane rigidity then that of the GDL. On the other hand, the intrusion of GDL into the channel was found to be about $\mathrm{I}_{\mathrm{GDL}}=$ $10 \mu \mathrm{m}$ due to an imposed displacement of $0.058 \mathrm{~mm}$ for a contact pressure of $\mathrm{P}=1 \mathrm{MPa}$. This implies that a contact pressure difference of $2 \mathrm{MPa}$ causes an intrusion difference of the GDL in the channel of about $18 \mu \mathrm{m}$. Therefore, minimizing the contact pressure reduces the intrusion of the GDL into the channel and thereafter keeps the hydraulic diameter of the channel constant. However, low contact pressure 
causes large Ohmic voltage drops, which leads to a decrease in the performance of the cell.

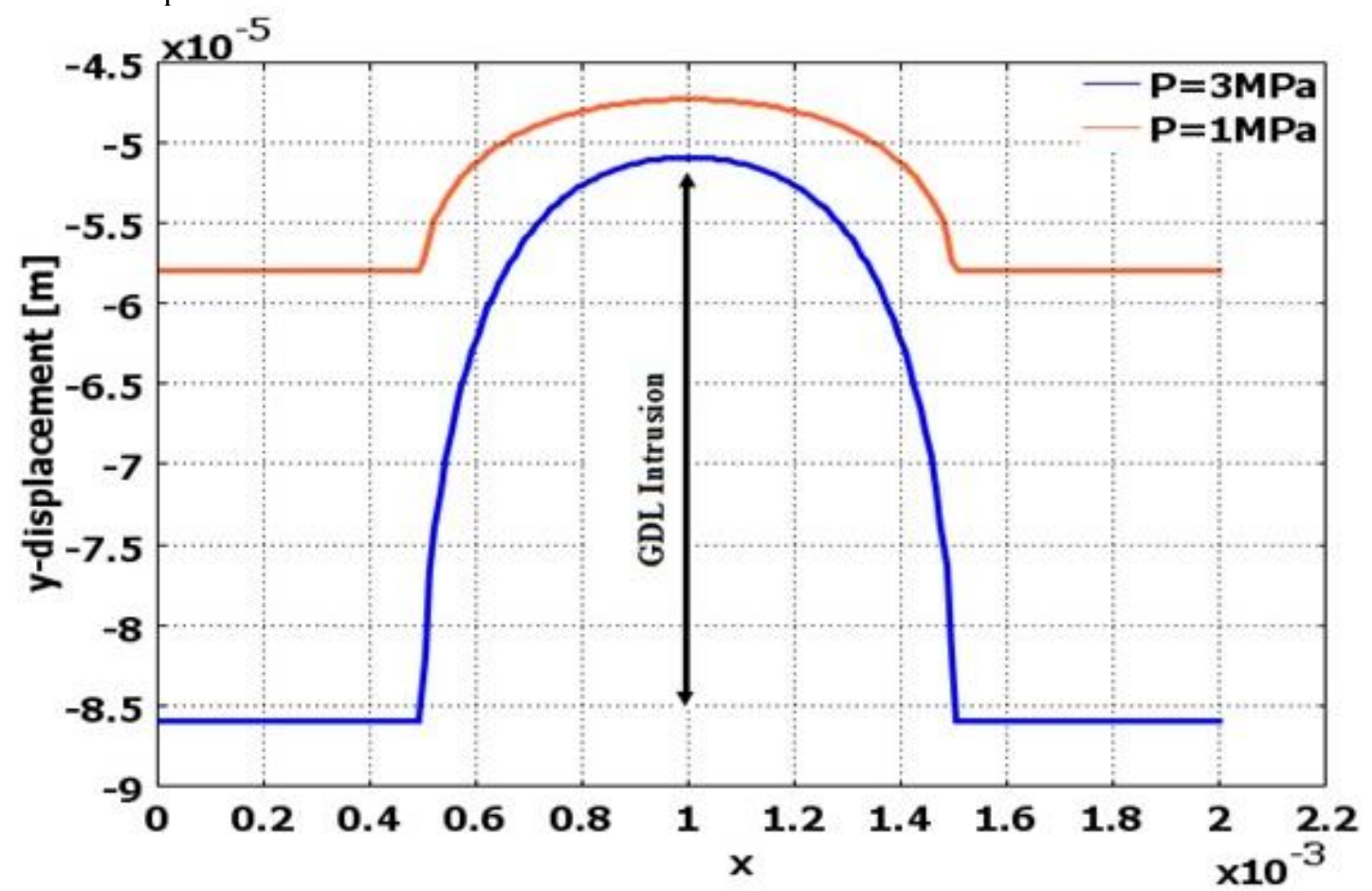

Figure 2. $\mathrm{Y}$-Displacement of the membrane at $\mathrm{RH}=30 \%, \mathrm{~T}=25^{\circ} \mathrm{C}$ in both of case: $\mathrm{P}=1 \mathrm{MPa}$ and $\mathrm{P}=3 \mathrm{MPa}$

\section{GDL and membrane stresses distribution}

In steady-state operation, the distribution of the stresses of Von Mises through the GDL and membrane was simulated for $(\mathrm{RH}=30 \%$ and $\mathrm{T}=$ $\left.25^{\circ} \mathrm{C}\right)$ with the same contact pressure level $(\mathrm{P}=3$ $\mathrm{MPa}$ ) (Figure 3). We note that the distribution of the

\section{Max: $3.715 e 7$}

stresses is non-uniform. This can be interpreted in terms of the difference in Young's modulus of materials of the unit studied on one side, and because of the inhomogeneous distribution of the contact pressure at the Channel / GDE interfaces and the tooth of the plate/GDE on another side.

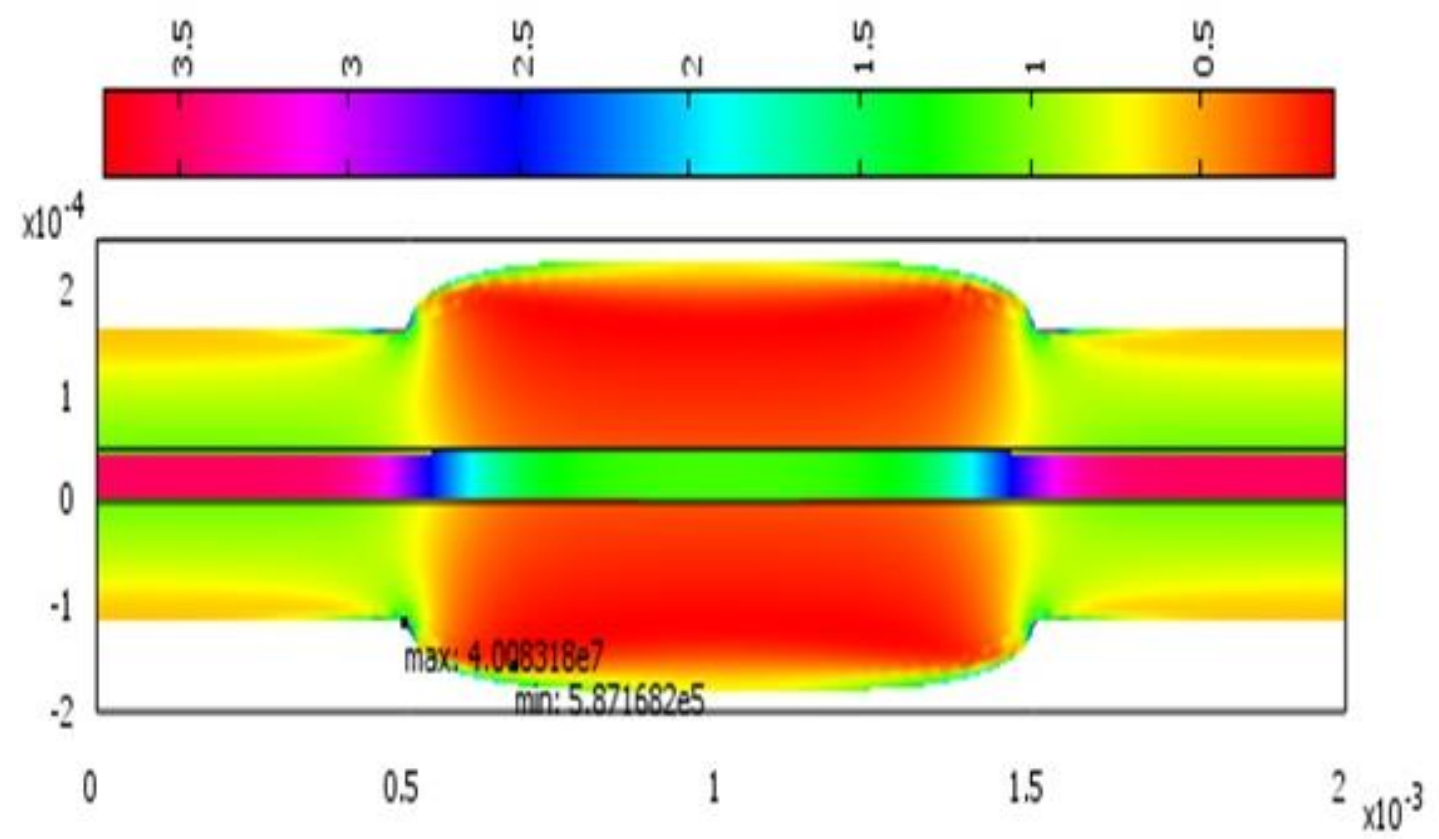

Figure 3. Distribution of Von Mises stress in the typical unit of the PEMFC at RH $=30 \%, \mathrm{~T}=25^{\circ} \mathrm{C}$ (Clamping phase) 
The maximum stress of van Misses is located in the GDL at the point of contact GDL/Channel/Bipolar plate. The maximum through-plane normal stress $\left(\sigma_{\mathrm{yy}}\right)$ in the membrane is always more important than that in the GDL and greatly exceed the elastic limit of the hydrated membrane ${ }^{34}$ (Figure 4). The latter is negative along the surface of the membrane; this corresponds to the state of the compression, which will subsequently cause permanent deformations.

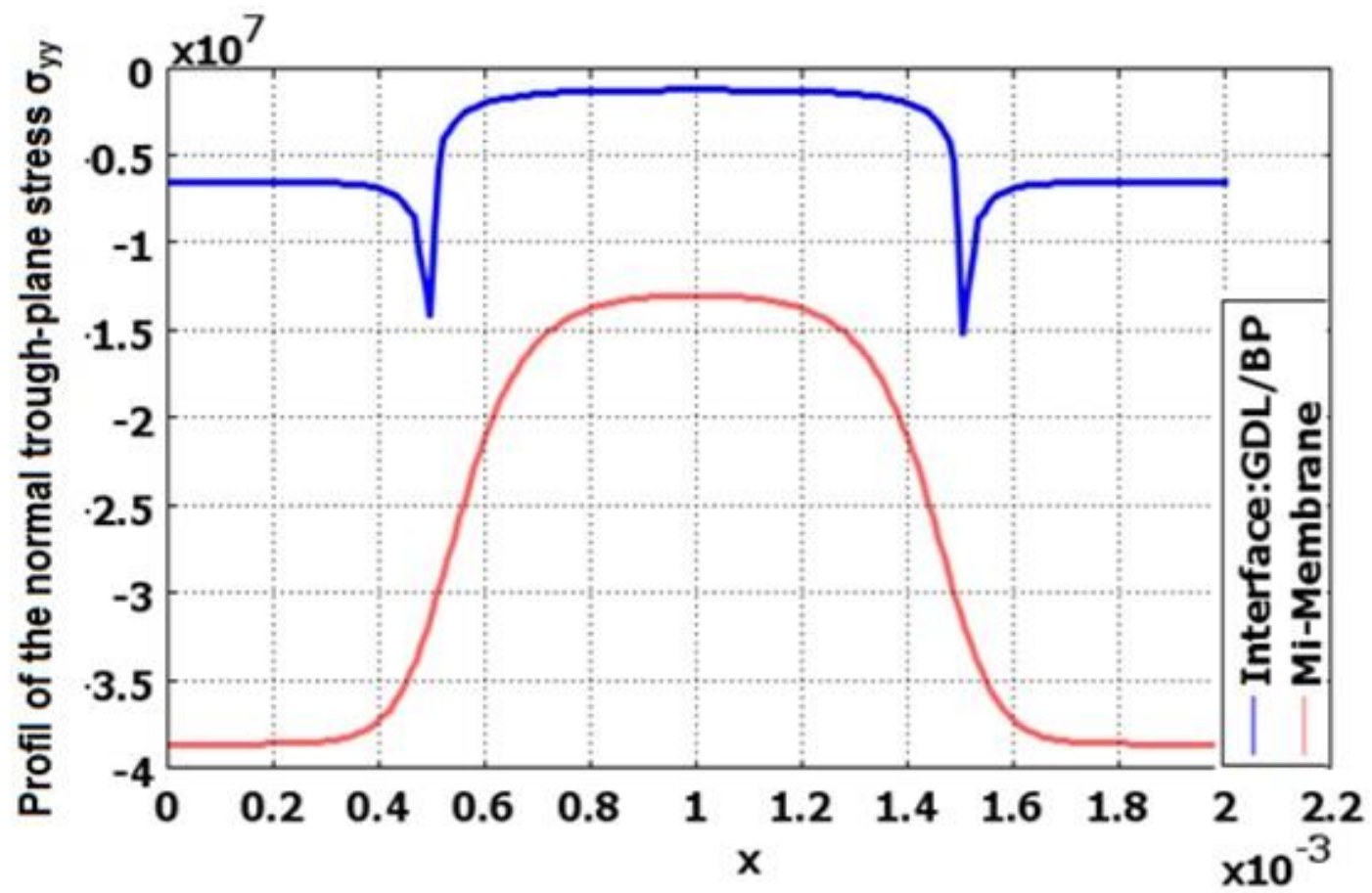

Figure 4. Profile of the normal trough-plane stress $\sigma_{\mathrm{yy}}(\mathrm{Pa})$ at $\mathrm{RH}=30 \%, \mathrm{~T}=25^{\circ} \mathrm{C}(\mathrm{Clamping}$ phase)

\section{Effect of variation of relative humidity}

In this section, we investigate the influence of the state of hydration on membrane and GDL stress. It can be seen that an increase in the relative humidity from
$30 \%$ to $90 \%$ causes an increase in the maximum Von Mises stress of GDL from 3.75 to 3.95 (Figure 3 and Figure 5). However, in the membrane, the maximum stress is low and equal to $2.55 \mathrm{MPa}$ (Figure 5).

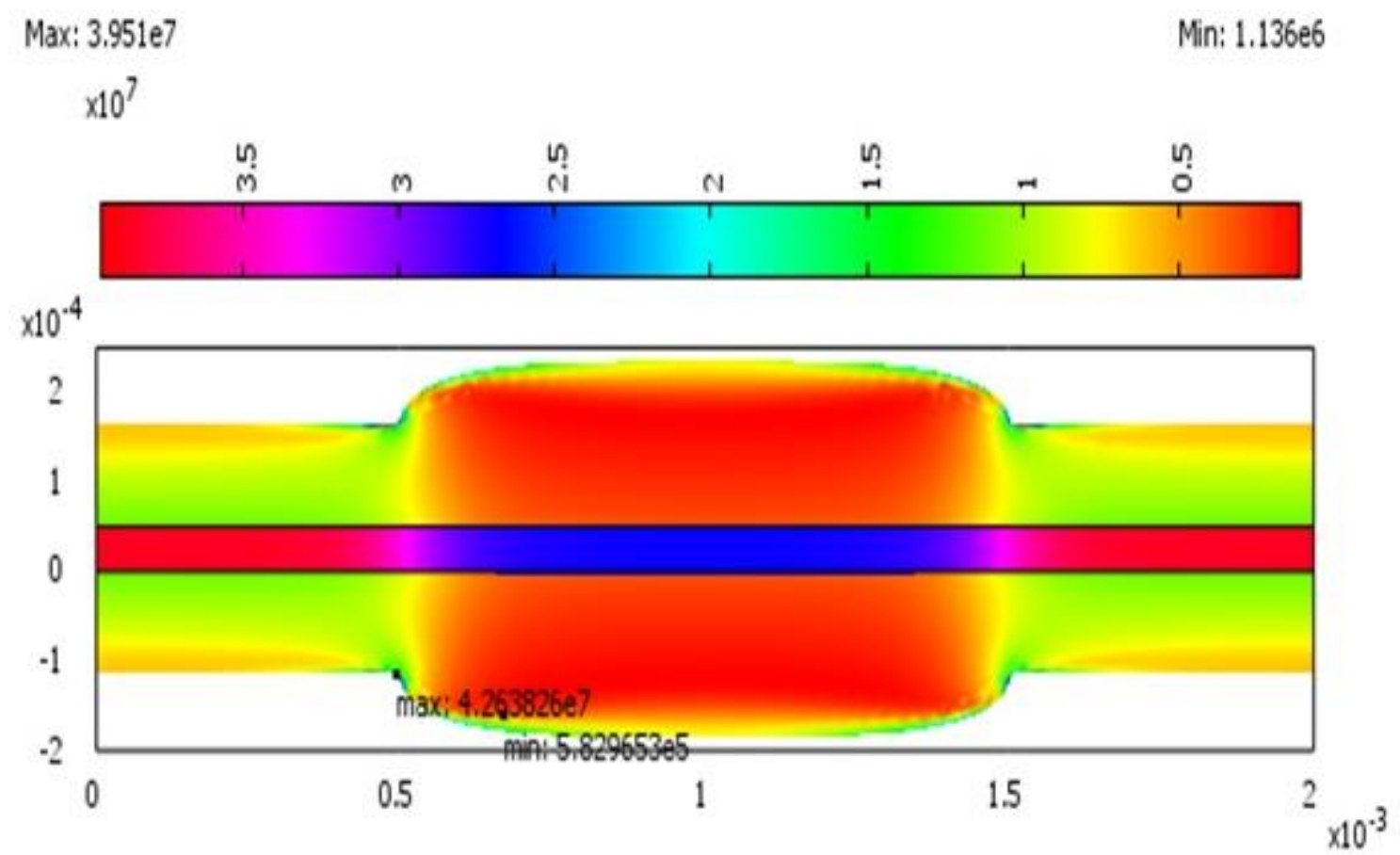

Figure 5. Distribution of Von Mises stress in the typical unit of the PEMFC at constant $\mathrm{T}=25^{\circ} \mathrm{C}$

(Loading phase: $\mathrm{RH}=90 \%$ ) 
It can be seen, from Figure 6 that the variation of gas $\mathrm{RH}$ from $30 \%$ to $90 \%$ produce stress approximately equal to $3.8 \mathrm{MPa}$ in the membrane.

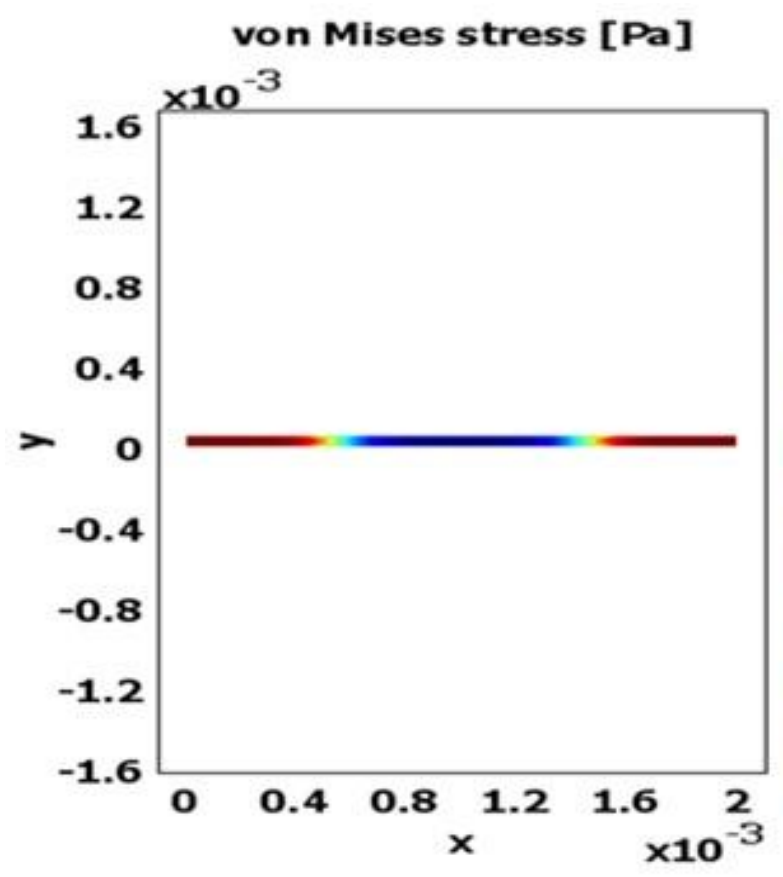

Consequently, these critical stress, with alternating start-up and shutdown cycles, can lead to the mechanical cracking of GDL ${ }^{35,34}$.

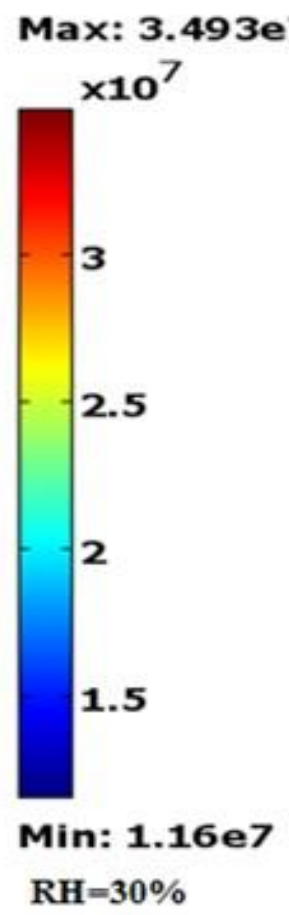

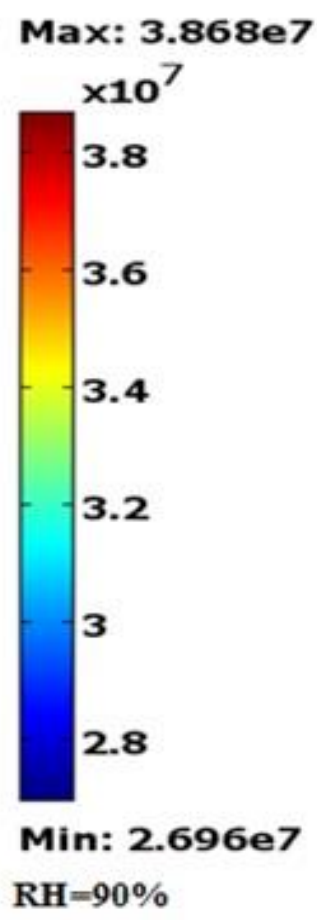

Figure 6. Distribution of Von Misses stress in the membrane at constant $\mathrm{T}=25^{\circ} \mathrm{C}$ (Loading phase: $\mathrm{RH}$ from $30 \%$ to $90 \%$ )

\section{Effect of variation of temperature}

Figure 7 allows us to simulate the intrusion of the GDL into the channel under the standard conditions of assembly of the cell stack $\left(\mathrm{T}=85^{\circ} \mathrm{C}\right)$ with a contact pressure of $\mathrm{P}=3 \mathrm{MPa}$ (clamping phase). The influence of the temperature variation is non-significant in generating stresses. Therefore, the increase in temperature from $25^{\circ} \mathrm{C}$ to $85^{\circ} \mathrm{C} \%$ causes an increase in the maximum Von Mises stress of $0.0836 \mathrm{MPa}$ (Figure 7 and Figure 3). The same results are observed, from Figure 8, for the membrane stress.

Max: $3.722 \mathrm{e} 7$

Min: $1.141 \mathrm{e} 6$

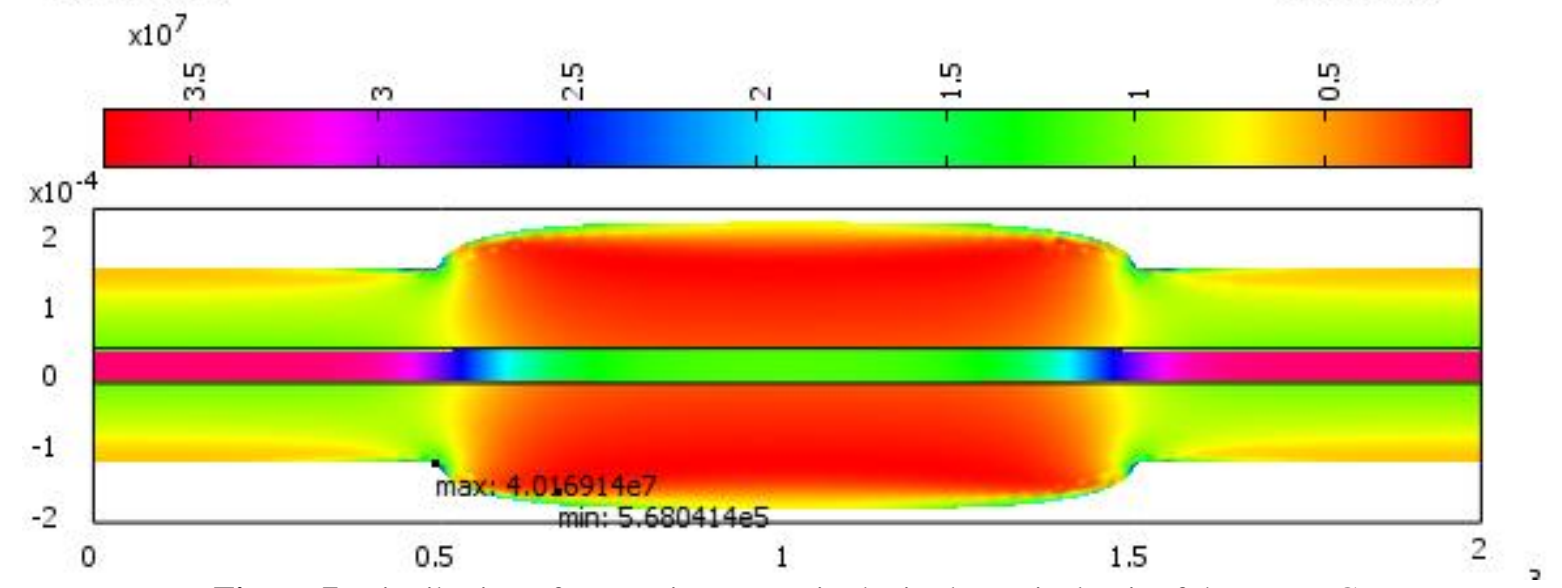

Figure 7. Distribution of Von Mises stress in the in the typical unit of the PEMFC

$\left(\mathrm{RH}=30 \%\right.$ and $\mathrm{T}=85^{\circ} \mathrm{C}$ ) 


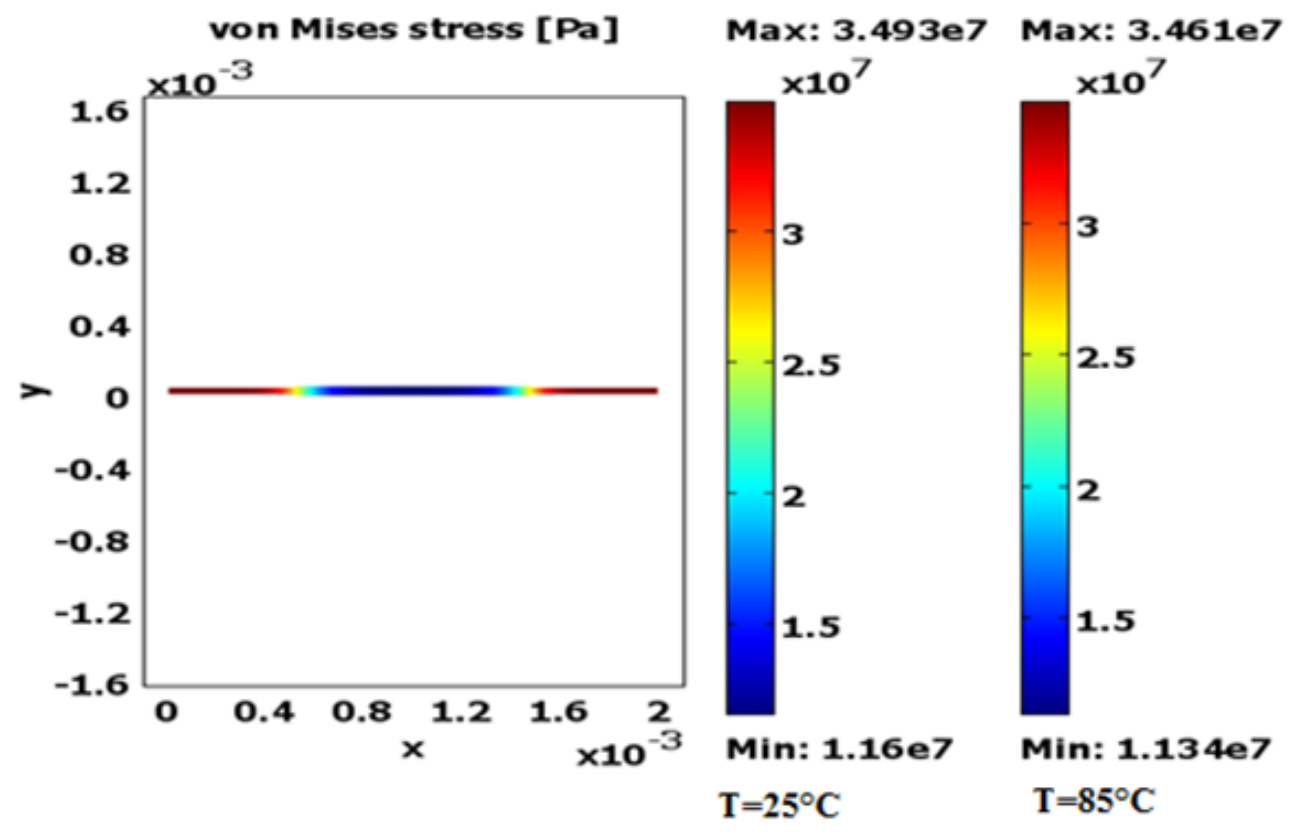

Figure 8. Distribution of Von Mises stress in the membrane at constant $\mathrm{RH}=30 \%$ (Loading phase: $\mathrm{T}$ from $25^{\circ} \mathrm{C}$ to $85^{\circ} \mathrm{C}$ )

\section{Conclusion}

In this study, we have analyzed the influence of the contact pressure and the hydrothermal operating conditions on the stress distribution and the deformations of a typical unit of a PEMFC. Indeed, the clamping force exerted on the terminal bipolar plates induces a significant contact pressure at the bipolar plate/GDL interface. This causes large deformations, and intense stresses in the gas diffusers (GDL) and the maximum stress of Von Mises was found at the intersection of the GDL/Bipolar plate/Flow channel. The analyze of the effect of relative humidity and operating temperature show that an increase in the relative humidity from $30 \%$ to $90 \%$ causes an increase in the maximum Von Mises stress of GD. Also, an increase in temperature from $25^{\circ} \mathrm{C}$ to $85^{\circ} \mathrm{C} \%$ causes an increase in the maximum Von Mises stress.

\section{References}

1- Y. Faydi, R. Lachat, Y. Meyer, Thermomechanical characterization of commercial Gas Diffusion Layers of a Proton Exchange Membrane Fuel Cell for high compressive pre-load sunder dynamic excitation Fuel. Journal of Power Sources, 2016, 182, 124-130.

2- Z. Zhang, Mechanical contact analysis on the interfaces in a proton exchange membrane fuel cell. Mécanique \& Industries, 2010, 11(3-4), 183-188.

3- S. Escribano, J. Blachot, J. Ethève, A. Morin, Modal Characterization of PEMFCS gas diffusion layers' properties. J. Power Sources, 2006, 156, 8-13.

4- S. D. Yim, B. J. Kim, Y. J. Sohn, Y. G. Yoon,
G. Park, W. Y. Lee, The influences of stack clamping pressure on the performance of PEM fuel cell stack. Curr Apply Phys., 2010, 59-61.

5- Y. Zhou, G. Lin, A. Shih, and Hu S J. Multiphysics modeling of assembly pressure effects on PEM fuel cell performance, ASME. Journal of Fuel Cell Science and Technology, 2008.

6- Y. Zhou, G. Lin, A. Shih, S.J. Hu, Assembly pressure and membrane swelling in PEM fuel cells. Journal of Power Sources, 2009, 192, 544-51.

7- J. L. Shuo, D. H. Chen, Ching-Han Huang, Analyses of the fuel cell stack assembly pressure. J. of Power Sources, 145, 2005, 353-361.

8- G.Jiabin, H. Andrew, L. Hongtan, Effect of gas diffusion layer compression on PEM fuel cell performance. Journal of Power Sources, 2006, 159, 922-927.

9- R. Montanini, G. Squadrito, G. Giacoppo, Realization of a uniform internal stress distribution for each cell component is therefore essential. XIX IMEKO World Congress Fundamental and Applied Metrology, September 2009, 6-11.

10-T. T. Chin, T. Lin, H. R. Shiur, The Effect of Clamping Pressure on Gas Diffusion Layer Performance in Polymer Electrolyte Fuel Cells. Journal of the Chinese Institute of Engineers. Journal of the Chinese Institute of Engineers, 2016, 39, 353-362.

11-L. Peng, Q. Diankai, Y. Peiyun, L. Ximin, Dimensional Error of Stamped Bipolar Plate and Gas Diffusion Layer in Proton Exchange Membrane Fuel Cell Stack Assembly. Journal of Electrochemical Energy Conversion and Storage, 2016, Vol. / 02,107-113.

12-A. El-Kharouf, W. R. Steinberger, The Effect of Clamping Pressure on Gas Diffusion Layer 
Performance in Polymer Electrolyte Fuel Cells. 2016.

13-Y. Zhou, C. Liu, J. Liang, L. Wang, Investigation of the effects of compression pressure on direct methanol fuel cell. Power Sources, 2011, 9, 196-264.

14-G. Maranzana, O. Lottin, T. Colinart, S. Chupin, S. Didier jean, A multi instrumented polymer exchange membrane fuel cell: Observation of the in-plane non homogeneities. Journal of Power Sources, 2008, Vol. 180, №2, 748-754

15-S. Basu, J. Li, C Y. Wang, Two-phase flow and mal distribution in gas channels of a polymer electrolyte fuel cell. Journal of Power Sources, 2009, 187, 431-443.

16-S. Haase, M. Rauber, Ex-situ gas diffusion layer intrusion effect determination of polymer electrolyte membrane fuel cell flow fields. 2015, 5-35.

17-S.G. Kandlikar, Z. Lu, TY. Lin, D. Cooke, M. Daino, Uneven gas diffusion layer intrusion in gas channel arrays of proton exchange membrane fuel cell and its effects on flow distribution. Power Sources, 2009, 194-328.

18-K. C. Neyerlin, H. A. Gasteiger, C. K. Mittelsteadt, J. Jorne, W. Gu, Effect of relative humidity on oxygen reduction kinetics in a PEMFC. J Electrochem Soc 2005, 152, A1073-1080.

19-A. Turhan, K. Heller, J.S. Brenizer, M.M. Mench, Quantification of liquid water accumulation and distribution in a polymer electrolyte fuel cell using neutron imaging. J Power Sources, 2006, 160, 1195-203.

20-R. L. Borup, J. R. Davey, F. H. Garzon, D. L. Wood, M.A. Inbody, PEM fuel cell electrocatalyst durability measurements. J Power Sources, 2006, 163, 76-81.

21-J. Zhang, Y. Tang, C. Song, Z. Xia, H. Li, $\mathrm{H}$. Wang, PEM fuel cell relative humidity $(\mathrm{RH})$ and its effect on performance at high temperature. Electrochim Acta, 2008, 53, 5315-5321.

22-W. Bi, Q. Sun, Y. Deng, TF. Fuller, The effect of humidity and oxygen partial pressure on the degradation of $\mathrm{Pt} / \mathrm{C}$ catalyst in PEM fuel cell. Electrochim Acta, 2009, 54, 1826-33.

23-K.H. Lim, H.S. Oh, S.E. Jang, Y.J. Ko, H.J. Kim, H. Kim, Effect of operating conditions on carbon corrosion in polymer electrolyte membrane fuel cells. J Power Sources, 2009, 193, 575-9.

24-K. Shinozaki, H. Yamada, Y. Morimoto, Relative humidity dependence of Pt utilization in polymer electrolyte fuel cell electrodes: effects of electrode thickness, ionomer-to-carbon ratio, ionomer equivalent weight, and carbon support. J Electrochem Soc, 2011, 158, B467-75.
25-L. Xing, M. Mamlouk, R. Kumar, K. Scott, Numerical investigation of the optimal Nafion ionomer content in cathode catalyst layer: an agglomerate two-phase flow modelling. Int J Hydrogen Energy 2014, 39, 9087-9104.

26-L. Xing, PK. Das, X. Song, M. Mamlouk, K. Scott, Numerical analysis of the optimum membrane/ionomer water content of PEMFCs: the interaction of Nafion ionomer content and cathode relative humidity. Appl Energy, 2015, 138, 242-257.

27-L. Xing, Q. Cai, C. Xu, C. Liu, K. Scott, Y. Yan, Numerical study of the effect of relative humidity and stoichiome-tric flow ratio on PEM (proton exchange membrane) fuel cell performance with various channel lengths: An anode partial flooding modelling, Energy, 2016, 106, 631-645.

28-A. Pablo, G. Salaberri, M. Vera, R. Zaera, Nonlinear orthotropic model of the inhomogeneous assembly compression of PEM fuel cell gas diffusion layers, International Journal of Hydrogen Energy, 36, 2011, 11856-11870.

29- J. Kleemann, F. Finsterwalder, W. Tillmetz, Characterization of mechanical behavior and couple electrical properties of polymer electrolyte membrane fuel cell gas diffusion layers. Journal of Power Sources, 190, 2009, 92-102.

30-E. Firat, P. Beckhaus, A. Heinzel, Finite Element Approach for the Analysis of the Fuel Cell Internal Stress Distribution. Proceeding of the COMSOL conference of Stuttgart, 2011.

31-O. Kyeongmin, C. Purushothama, J. Hyunchul, Numerical study of thermal stresses in high temperature proton exchange membrane fuel cell (HT-PEMFC). International journal of hydrogen energy39, 2014, 2785-2794.

32- Y. Tang, A. Karlsson, M. Santare, M. Gilbert, S. Cleghorn, W. Johnson, An experimental investigation of humidity and temperature effects on the mechanical properties of perfluorosulfonic acid membrane. J. Mater. Sci., 2006, 425, 297-304.

33-E. Sadeghi, N. Djilali, M. Bahrami, Effective thermal conductivity and thermal contact resistance of gas diffusion layers in proton exchange membrane fuel cells. Journal of Power Sources, 2011, 196, 246-254.

34- A. Kusoglu, A. M. Karlsson, M. Santare, S. Cleghorn, W. B. Johnson, Mechanical response of fuel cell membranes subjected to a hygro thermal cycle. J Power Sources, 2006, 161, 987-996.

35-D. Bograchev, M. J. Gueguen, S. Grandidier, S. Martemianov, Stress and plastic deformation of MEA in fuel cell Stresses generated during cell assembly. Journal of Power sources, 2008, 180, 393-401. 